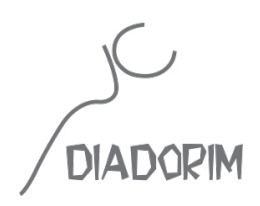

\title{
NOTA PRELIMINAR SOBRE AS ORIGENS E OS DESDOBRAMENTOS DA HISTORIOGRAFIA DA LITERATURA PORTUGUESA ${ }^{1^{*}}$
}

\author{
Roberto Acízelo de Souza²
}

DOI:10.17074/1980-2552.2016n17v1p12

\section{RESUMO:}

Descreve-se o processo de constituição e consolidação da historiografia da literatura portuguesa no século XIX, com notícia tanto de seus antecedentes nos séculos XVII e XVIII quanto de seus desdobramentos no XX e no XXI.

PALAVRAS-CHAVE: historicismo; século XIX; nação; nacionalidade

\begin{abstract}
:
It is described the process that led to the constitution and consolidation of the Portuguese literature historiography in the $19^{\text {th }}$ century, together with a brief on its antecedents in the $17^{\text {th }}$ and $18^{\text {th }}$ centuries, as well as on its extensions in the $20^{\text {th }}$ and $21^{\text {st }}$ centuries.
\end{abstract}

KEYWORDS: historicism; $19^{\text {th }}$ century; nation; nationality

Analogamente ao que se passou em outros países da Europa e da América, a historiografia literária nacional portuguesa, no formato moderno de narrativa generalista orientada etiológica e teleologicamente, se constitui e se consolida no século XIX, com antecedentes nos séculos XVII e XVIII.

Nosso propósito aqui é esboçar uma reconstituição sintética do itinerário que conduziu das primeiras tentativas a produtos mais acabados, descrevendo seus marcos principais e suas suces-

1 *Versão revisada e atualizada de ensaio publicado em: Navegações: Revista de Cultura e Literaturas de Língua Portuguesa. Porto Alegre: Programa de Pós-Graduação em Letras da PUCRS; Centro de Literaturas de Expressão Portuguesa da Universidade de Lisboa (CLEPUL), v. 2, n. 1, p. 44-48, jan./jun. 2009.

2 Professor Titular de Literatura Brasileira - Universidade do Estado do Rio de Janeiro.

Diadorim, Rio de Janeiro, Revista 17 volume 1, p. 12-19, Julho 2015. 
sivas etapas. Nada pretendemos além de uma apresentação concisa das obras e autores integrantes do processo, como primeira providência para um futuro aprofundamento crítico e analítico da questão.

No século XVII, não existe ainda a ideia de uma história literária panorâmica, situação que, de resto, como se sabe, não é privativa de Portugal. Assim, no espaço lusitano, o que mais se aproxima desse gênero de estudos encontra-se nas biografias isoladas de autores específicos: a de Camões, por Pedro Mariz, e a de Sá de Miranda, por Gonçalo Coutinho; as de Camões, João de Barros e Diogo do Couto, por Manuel Severim de Farias; a de D. Francisco de Portugal, por Francisco Luís de Vasconcelos (cf. Salgado Júnior, 1973, p. 394-395).

Outra espécie de produção integrante dessa por assim dizer proto-historiografia literária seiscentista consiste em simples listagens de escritores e suas respectivas obras, acompanhados de considerações críticas sumárias. Representa essa modalidade o Theatrum lusitaniae litterarium sive Bibliotheca scriptorum omnium lusitanorum, que permaneceu inédito em livro; representam-na também o Elogio dos poetas lusitanos, de Jacinto Cordeiro, bem como passagens das Cartas familiares e do Hospital das letras, de Francisco Manuel de Melo, e das Flores de España, de Antônio de Sousa Macedo (cf. ibid., p. 394-395).

Nos século XVIII, a grandiosa Biblioteca lusitana, de Diogo Barbosa Machado, constitui a principal referência entre os antecedentes da história literária propriamente dita. Obra de igreja digamos assim -, sua elaboração e publicação se arrastou ao longo de 18 anos, com intervalos mais ou menos longos entre os sucessivos quatro volumes, publicados respectivamente em 1741, 1747, 1752 e 1759. Inicia-se com uma carta ao rei, encomiástica e retórica, como era de rigor na época, a que se segue um prólogo em que o abade Barbosa caracteriza o gênero biblioteca e traça-lhe a história. O texto em si consiste em verbetes sobre escritores, dispostos em ordem alfabética e de extensão muito variada, porém de estrutura homogênea: biografia sintética do autor seguida pela lista de suas respectivas obras, ora com apreciação crítica, ora com simples descrição dos títulos inventariados.

Na segunda metade do século e na passagem para o XIX, temos ainda outros trabalhos representativos desse despertar para a histografia da literatura em terras portuguesas. É o caso das Memórias para a história literária de Portugal e seus domínios: divididas em várias cartas (1774), de João Pedro do Vale, pseudônimo de Antônio Félix Mendes (cf. Abreu, in Bolognini, 2003, p. 48), bem como o de alguns estudos integrantes das Memórias da literatura portuguesa publicadas pela Academia Real das Ciências de Lisboa (8 v., 1792-1814), especialmente "Memória sobre a poesia bucólica dos poetas portugueses", de Joaquim Foyos, e "Das origens e progressos da poesia portuguesa”, de Antônio Ribeiro dos Santos (cf. ibid., p. 42-43).

Por fim, mencionemos o Dicionário bibliográfico português, de Inocêncio Francisco da Silva e sucessores, obra cuja publicação se inicia na segunda metade do século XIX, mas segue o modelo setecentista da Biblioteca do abade Barbosa, inclusive na circunstância de que, mais do que obra de igreja, demandou um tempo de construção comparável ao das antigas catedrais. 
Assim, seu primeiro volume é de 1858, ao passo que o último, o vigésimo segundo, saiu em 1923, 65 anos depois, por conseguinte. Até o volume 8, de 1867, Inocêncio Francisco da Silva é seu único autor; a partir do volume 9 (1870), inicia-se a série dita "suplemento", entrando como coautor Pedro Venceslau de Brito Aranha, devendo ainda assinalar-se que no volume 21 (1914) registra-se a participação de J. J. Gomes de Brito, e que no volume 22 atuam na revisão, além de Gomes de Brito, também Álvaro Neves. ${ }^{3}$ Refletindo o estado de coisas da época em que começa a ser publicada - meados do século XIX, como vimos —, momento em que as literaturas nacionais de Portugal e do Brasil ainda não se achavam claramente apartadas, a obra arrola autores dos dois grandes ramos da produção literária em língua portuguesa, conforme esclarece o seu subtítulo: "estudos aplicáveis a Portugal e ao Brasil".

\section{4}

Somente no século XIX, conforme antecipamos, o labor historiográfico no campo da literatura portuguesa assume apresentação narrativa. É o momento de ascensão do historicismo, quando se instala uma espécie de amplo pressuposto epistemológico, segundo o qual as coisas só são se dispuserem de uma história, ou, em outros termos, as coisas são a sua história. Assim, se a literatura portuguesa existe, então possui uma história, que afinal constitui o seu próprio ser. Torna-se desse modo imperioso narrar essa história, concebida como o esforço da nacionalidade no sentido de alcançar expressão literária própria.

A história da literatura, assim, concebida sob um difuso hegelianismo, constitui uma épica do espírito. Implica correlativamente uma etiologia e uma teleologia, isto é, concretiza-se numa narrativa que tanto especula sobre as origens da cultura literária da nação - tidas por manifestações como que apenas premonitórias de um futuro a alcançar - quanto dispõe sobre a sua finalidade, o seu destino: a plena encarnação da ideia do nacional na produção literária.

No que diz respeito a Portugal, inauguram esse novo modo de construir uma imagem da literatura - moderno e romântico por excelência, e bem distinto das representações antigas e clássicas, tipificadas na retórica, na poética e nas "bibliotecas" - alguns autores estrangeiros.

O primeiro deles é o alemão Friedrich Bouterwek, cuja História da poesia e da eloquência portuguesa (1805) constitui o volume 4 da obra História da poesia e da eloquência desde o fim do século XIII, que por sua vez consta de 12 volumes publicados de 1801 a 1819.

Em seguida, vem a contribuição do suíço Simonde de Sismondi, com a seção dedicada a Portugal - a parte final do quarto e último volume - de sua obra Sobre a literatura do meio-dia da Europa (1813).

Fecha o ciclo desses trabalhos inaugurais devidos a estrangeiros o estudo do lusitanista francês Ferdinand Denis, intitulado Resumo da história literária de Portugal, seguido do Resumo da história literária do Brasil, publicado no ano de $1826 .{ }^{4}$

3 O Dicionário de Inocêncio, como se tornou conhecido, gerou duas obras derivadas: o Aditamento ao Dicionário bibliográfico português de Inocêncio Francisco da Silva (Coimbra: Imprensa da Universidade, 1927), de Martinho da Fonseca, e o Índice alfabético do Dicionário bibliográfico português de Inocêncio Francisco da Silva (São Paulo: Departamento de Cultura / Divisão de Bibliotecas, 1938), de José Soares de Sousa.

4 Encontramos ainda sumárias referências a dois outros estrangeiros que devem figurar na relação: François Diadorim, Rio de Janeiro, Revista 17 volume 1, p. 12-19, Julho 2015. 
Nesse mesmo ano, Almeida Garrett dá início à produção nacional no campo da história literária. Sua monografia figura como introdução à antologia de poesia Parnaso lusitano (1826), intitulando-se "História abreviada da língua e poesia portuguesa", título depois alterado para "Bosquejo da história da poesia e língua portuguesa", quando de sua integração às Obras completas do autor a partir da edição de 1904.

Apesar da precedência cronológica de Garrett, Francisco Freire de Carvalho reivindica pioneirismo no campo que nos ocupa, como se vê pelo título que atribuiu ao seu estudo - Primeiro ensaio sobre história literária de Portugal —, publicado em 1845, mas com a redação iniciada em 1814, conforme declara o autor (Carvalho, 1845, p. 3). Independentemente dessa questão de primazia de publicação, uma coisa, contudo, é certa: Freire de Carvalho é o primeiro a estender o relato até os eventos literários seus contemporâneos, uma vez que Garrett não ultrapassou o século XVIII na sua história.

À contribuição de Freire de Carvalho segue-se a de José Maria da Costa e Silva. A exemplo de Garrett, o autor não ultrapassa o século XVIII nos 10 volumes do seu Ensaio biográfico-crítico sobre os melhores poetas portugueses, publicados de 1850 a 1855. A rigor, no entanto, a contribuição de Costa e Silva, segundo, aliás, indica o título da obra, constitui mais uma sucessão de biografias do que uma história literária narrativamente integrada, chegando inclusive em alguns casos a quebrar a ordem cronológica no ordenamento de seus volumes e capítulos.

Esse mesmo ano de 1850 constitui a data provável em que o brasileiro Manuel Antônio Álvares de Azedo escreveu o seu longo ensaio "Literatura e civilização em Portugal", publicado postumamente no primeiro volume das Obras do poeta, aparecido em 1853. Com ele se inaugura uma tradição de dedicadas e entusiásticas intervenções brasileiras no processo de construção da história literária de Portugal, pois, como se verá adiante, a Álvares de Azevedo, nessa trilha, seguem-se Joaquim Caetano Fernandes Pinheiro, Francisco Sotero dos Reis, Massaud Moisés, Segismundo Spina, Antônio Soares Amora. ${ }^{5}$

Na década de 1850 registra-se ainda o projeto de José Silvestre Ribeiro. Seu trabalho, entretanto, pelo menos segundo o que nos foi possível depreender a partir do prefácio do que chegou a publicar, esteve longe de alcançar o desenvolvimento planejado. Desse modo, os Primeiros traços duma resenha da literatura portuguesa não ultrapassaram o que seria o primeiro volume de uma série, publicado em 1853, consistindo apenas numa espécie de introdução teórica para o estudo historiográfico da literatura portuguesa.

Villemain (cf. Salgado Júnior, 1973 [1959], p. 395) e A. M. Sane, este último autor de "Introdução sobre a literatura portuguesa, com notas históricas, geográficas e literárias” (1808) (cf. Abreu, in Bolognini, 2003, p. 53). Assinalamos, porém, que não nos foi possível acesso a essas obras.

5 Observe-se que, ao longo dos séculos XIX e XX, a lusofilia, em matéria tanto cultural quanto política, sempre integrou o nacionalismo brasileiro, por paradoxal que isso possa parecer à primeira vista, tendo sido tão comum quanto as atitudes antilusitanas, se é que não prevaleceu sobre estas. Nesse sentido, vejam-se duas manifestações contraditórias no campo dos estudos literários, mais ou menos contemporâneas: enquanto Álvares de Azevedo, no ensaio referido, manifesta apreço e orgulho por poetas portugueses, considerando-os nossos e desdenhando de certo nacionalismo que pretendia expurgá-los da literatura brasileira (cf. Azevedo, 2000 [circa 1850], p. 715), Junqueira Freire, numa página de raivosa lusofobia, acusa os portugueses de terem assassinado Antônio José da Silva e Cláudio Manuel da Costa, e de terem ainda intimidado Basílio da Gama, segundo ele fundadores respectivamente da dramaturgia, da lírica e da épica brasileiras (cf. Freire, 1869 [1852], p. 49-51).

Diadorim, Rio de Janeiro, Revista 17 volume 1, p. 12-19, Julho 2015. 
Na sequência cronológica, após os esboços mencionados, devidos a estrangeiros, a portugueses e a um brasileiro, a historiografia literária de Portugal ganharia desenvolvimento mais extenso e minucioso na obra de dois outros brasileiros.

Assim, em 1862 o cônego fluminense Joaquim Caetano Fernandes Pinheiro publicaria o Curso elementar de literatura nacional. Apesar do título, que, dada a nacionalidade do autor, em princípio parece indicar restrição do âmbito do livro à literatura do Brasil, na verdade a obra se ocupa com a literatura da língua portuguesa, sendo de assinalar-se, por sinal, que a literatura portuguesa ocupa espaço maior do que o reservado à brasileira. Mais tarde, em 1873, com o seu Resumo de história literária, o autor voltaria a contribuir para a história da literatura portuguesa, pois o segundo volume da obra é dedicado às letras da língua portuguesa, aí compreendidas, como no Curso, as literaturas nacionais de Portugal e do Brasil.

O outro brasileiro que na mesma década viria a inscrever-se entre os historiadores da literatura lusa é o maranhense Francisco Sotero dos Reis. A ele devemos um extenso Curso de literatura portuguesa e brasileira, cujos cinco volumes foram sendo publicados de 1866 a 1873, e no qual, a exemplo do que se observa na obra de Pinheiro Fernandes, à literatura de Portugal se reserva espaço bem maior do que o concedido à literatura brasileira.

Um pouco depois dessas contribuições brasileiras mais desenvolvidas, Teófilo Braga, com sua extensa História da literatura portuguesa, viria a consolidar de vez a historiografia literária de Portugal. Trata-se de projeto tumultuário e ambicioso, totalizando 10 volumes publicados de 1869 a 1872, ${ }^{6}$ e que geraria três desdobramentos: uma fundamentação teórica - Teoria da história da literatura portuguesa (1872) —, uma redução didática - Manual da história da literatura portuguesa (1875) - e uma edição refundida (1909).

A década de 1870, por sua vez, assistirá a uma colaboração fortuita entre José Maria de Andrade Ferreira e Camilo Castelo Branco. É que o primeiro morreu tendo publicado o volume 1 de um Curso de literatura portuguesa (1875), tendo o segundo seguido o seu plano e dado continuidade ao projeto, originando-se assim obra homônima de sua autoria, publicada em 1876.

\section{5}

Consolidada, como vimos, na segunda metade do Oitocentos, a historiografia literária portuguesa continuaria tendo cultores no século XX.

Na década de 1930, aparece decaída em manuais de objetivos estritamente escolares, encontrando-se representada pela História da literatura portuguesa de Joaquim Mendes dos Remédios $(1930)^{7}$ e pelo trabalho homônimo de Joaquim Ferreira (1939).

\footnotetext{
6 João Palma-Ferreira contabiliza 11 volumes (em Braga, 1984, v. 1, p. 8), talvez por considerar parte da obra o livro Teoria da história da literatura portuguesa (1872).

7 Segundo informa João Palma-Ferreira, “em 1914 já ia [a obra] em 3a edição" (em Braga, 1984, v. 1, p. 53), não nos tendo sido possível apurar com segurança a data da primeira. Acreditamos, contudo, que terá sido 1898, sob o título de Literatura portuguesa: esboço histórico, obra que, por sua vez, parece ser o segundo volume de outra publicada pelo mesmo editor no mesmo ano, apresentada como segunda edição e intitulada Introdução à história da literatura portuguesa. Nesta última, não obstante o título, não se entra propriamente no tema por ele anunciado, havendo três grandes partes, ao que parece concebidas como preâmbulo para uma história da literatura portuguesa: Filologia portuguesa (que trata das origens da língua portuguesa, seus dialetos e relações com outros idiomas), Diadorim, Rio de Janeiro, Revista 17 volume 1, p. 12-19, Julho 2015.
} 
Nas décadas subsequentes, contudo, recupera o nível, reavendo veleidades propriamente intelectuais. Assim, aparece, em 1944, a História da literatura de Portugal, de Fidelino de Figueiredo, e em 1955 surge a História da literatura portuguesa de Antônio José Saraiva e Óscar Lopes.

A década de 1960, por seu turno, veria retomada a tradição de participação brasileira no processo de elaboração da história literária de Portugal. Publicam-se então o volume A literatura portuguesa (1960), assinado por Massaud Moisés, bem como os três volumes de Presença da literatura portuguesa (1966), de que são coautores Segismundo Spina, Antônio Soares Amora e Massaud Moisés.

\section{6}

Para arrematar essa notícia sumária, assinalemos que, na passagem do século XX para o XXI, não obstante o pouco interesse que a história literária de modelo romântico-realista vem despertando nesses tempos por assim dizer pós-nacionalistas, observam-se projetos de reciclagem dessa tradição, concretizados em trabalhos produzidos por equipes. Assim, temos notícia de três empreendimentos nessa direção.

Um deles teve a direção do professor Massaud Moisés, tendo resultado em quatro volumes, com o título geral de Literatura portuguesa em perspectiva, e subtítulos específicos por volume: 1 - “Trovadorismo e humanismo" (1992), 2 - "Classicismo, barroco, arcadismo" (1993), 3 - "Romantismo e realismo" (1994) e 4 - "Simbolismo e modernismo" (1994). ${ }^{8}$

Um outro projeto - História crítica da literatura portuguesa - é dirigido pelo professor Carlos Reis. Prevista para nove volumes, a obra começou a ser publicada em 1993, tendo saído até o momento os de número 1 (1998), 2 (1999), 3 (2001), 4 (2010), 5 (1993), 6 (2000), 7 (2004) e 9 (2005), prevendo-se a publicação do volume 8 ainda para o ano em curso, 2015.

Uma terceira obra conta com a coordenação da professora Isabel Allegro de Magalhães. Trata-se de História e antologia da literatura portuguesa, que começou a ser publicada em 1997, sob a forma de fascículos numerados, tendo atingido, até onde nos foi possível acompanhar, o de número 30, datado de 2004.

Esses trabalhos dedicados à historiografia literária portuguesa, publicados ou em processo de publicação a partir da última década do século passado, apresentam em comum o propósito de romper com os esquemas tradicionais da disciplina. Assim, num ambiente acadêmico refratário à história literária, com pronunciada tendência, por conseguinte, a rejeitar os elementos identificadores dessa disciplina - tais como a assunção de um conceito simplista de literatura, a linearidade evolucionista, o nacionalismo isolacionista e acrítico, a magnificação da importân-

\footnotetext{
Literatura grega e Literatura latina.

8 Como se vê, a participação brasileira na elaboração da historiografia literária de Portugal vem-se revelando uma constante histórica. Assim, temos contribuições que figuram entre as pioneiras - Álvares de Azevedo, Fernandes Pinheiro, Sotero dos Reis -, continuidade dessa tradição no século XX — Massaud Moisés, Antônio Soares Amora, Segismundo Spina - e presença no processo ora em curso de revisão e revitalização da disciplina - Massaud Moisés. Isso naturalmente se harmoniza com a estabilidade institucional da matéria no sistema de ensino brasileiro, particularmente universitário, onde literatura portuguesa há muito assumiu posição paritária com literatura brasileira. Por outro lado, que nos conste, só há uma obra de historiografia literária brasileira devida a autor português: trata-se de História breve da literatura brasileira, de José Osório de Oliveira, publicada em 1939, e cuja reedição mais recente saiu em 1964.

Diadorim, Rio de Janeiro, Revista 17 volume 1, p. 12-19, Julho 2015.
} 
cia das condições contextuais (étnicas, históricas, culturais, sociais, econômicas) —, todas se propõem não reduplicar o historicismo à maneira do Oitocentos, mas introduzir diferenciais capazes de revitalizar a pesquisa historiográfica. Assim, nos três projetos vemos a superação das histórias literárias autorais, em favor de empreendimentos coletivos. Além disso, em todos eles se pretere o rótulo rotineiro de "História da literatura portuguesa", em favor de títulos que apontam para o propósito de renovação da disciplina, ora pela ênfase na atitude crítica - caso das obras dirigidas respectivamente por Carlos Reis e Massaud Moisés ${ }^{9}$-, ora pela composição com outro gênero, a antologia, caso dos volumes coordenados por Isabel Allegro de Magalhães.

\section{Referências}

AZEVEDO, [Manuel Antônio] Álvares de. Literatura e civilização em Portugal [circa 1850]. In: . Obra completa. Organização de Alexei Bueno. Rio de Janeiro: Nova Aguilar, 2000. p. 706744.

BOLOGNINI, Carmen Zink (Org.). História da literatura: o discurso fundador. Campinas, SP: Mercado de Letras / Associação de Leitura do Brasil; São Paulo: Fapesp, 2003.

BRAGA, Teófilo. História da literatura portuguesa: introdução. Porto: Imprensa Portuguesa Ed., 1870. Teoria da história da literatura portuguesa: dissertação para o concurso da $3^{\text {a }}$ cadeira (Literaturas modernas da Europa e especialmente a Literatura portuguesa) do Curso Superior de Letras. Porto: Imprensa Portuguesa, 1872.

. Manual da história da literatura portuguesa: desde as suas origens até ao presente. Porto: Magalhães \& Moniz, 1875.

História da literatura portuguesa. [Lisboa]: Imprensa Nacional-Casa da Moeda, 1984 [1869-1872]. $4 \mathrm{v}$.

BRANCO, Camilo Castelo. Curso de literatura portuguesa. Prefácio de Viale Moutinho. Lisboa: Labirinto, [1876].

CARVALHO, Francisco Freire de. Primeiro ensaio sobre história literária de Portugal: desde a sua mais remota origem até o presente tempo, seguido de diferentes opúsculos, que servem para sua maior ilustração, e oferecido aos amadores da literatura portuguesa em todas as nações. Lisboa: Tipografia Rolandiana, 1845.

FERREIRA, Joaquim. História da literatura portuguesa. Porto: Domingos Barreira Editor, 1939. FIGUEIREDO, Fidelino. História literária de Portugal: séculos XII-XX. São Paulo: Companhia Ed. Nacional, 1966 [1944].

FREIRE, Luís José Junqueira. Elementos de retórica nacional. Introdução de Franklin Dória. Rio de Janeiro: Eduardo \& Henrique Laemmert, 1869.

9 Na obra dirigida por Carlos Reis, o próprio título explicita o propósito de aproximação entre história e crítica; na dirigida por Massaud Moisés, por seu turno, tal propósito aparece formulado na "Nota prévia", onde se lê que a obra consistiria numa “ historiografia crítica, e não meramente descritiva [...]” (Moisés, dir., 1992-1994, v. 1, p. 8). Diadorim, Rio de Janeiro, Revista 17 volume 1, p. 12-19, Julho 2015. 
GARRETT, Almeida [João Batista da Silva Leitão]. Bosquejo da história da poesia e língua portuguesa [1826]. In: Obra completa. Lisboa: Discolivro, 1984. V. 13, p. 269-316.

MACHADO, Diogo Barbosa. Biblioteca lusitana: histórica, crítica e cronológica - na qual se compreende a notícia dos autores portugueses e das obras, que compuseram desde o tempo da promulgação da Lei da Graça até o tempo presente [...]. Lisboa: Oficina de Antônio Isidoro da Fonseca (v.1) / Oficina de Inácio Rodrigues (v. 1 e 2) / Oficina Patriarcal de Francisco Luís Ameno (v. 4), 1741-1759. $4 \mathrm{v}$.

MAGALHÃES, Isabel Allegro de [Org.]. História e antologia da literatura portuguesa. Lisboa: Fundação Calouste Gulbenkian, 2007-2008. 4 v.

MOISÉS, Massaud. A literatura portuguesa. São Paulo: Cultrix, 1970 [1960].

(Dir.). A literatura portuguesa em perspectiva. São Paulo: Atlas, 1992-1994. 3 v.

OLIVEIRA, José Osório de. História breve da literatura brasileira. Lisboa: Inquérito, [1939].

PINHEIRO, [Joaquim Caetano] Fernandes (cônego). Resumo de história literária. Rio de Janeiro: B. L. Garnier, [1873]. 2 v.

. Curso elementar de literatura nacional. Rio de Janeiro: B. L. Garnier, 1883 [1862].

REIS, Carlos (Dir.). História crítica da literatura portuguesa. Lisboa / São Paulo: Verbo, 19932009. $9 \mathrm{v}$.

REIS, Francisco Sotero dos. Curso de literatura portuguesa e brasileira. [São Luís]: s.n., 1866$1873.5 \mathrm{v}$.

REMÉDIOS, [Joaquim] Mendes dos. Introdução à história da literatura portuguesa. Coimbra: F. França Amado, 1898.

. Literatura portuguesa: esboço histórico. Coimbra: França Amado, 1898.

. História da literatura portuguesa: desde as origens até a actualidade. Coimbra: Atlândida, 1930.

RIBEIRO, José Silvestre. Primeiros traços duma resenha da literatura portuguesa. Lisboa: Imprensa Nacional, 1853. v. 1.

SALGADO JÚNIOR, António. História literária em Portugal. In: COELHO, Jacinto Prado (Dir.) Dicionário de literatura. Porto: Figueirinhas; Rio de Janeiro: José Aguilar, 1973 [1959]. V. 1, p. 394-398.

SARAIVA, António José; LOPES, Oscar. História da literatura portuguesa. Santos, SP: Martins Fontes, 1973 [1955].

SILVA, Inocêncio Francisco da et alii. Dicionário bibliográfico português: estudos aplicáveis a Portugal e ao Brasil. Lisboa: Imprensa Nacional, 1858-1923. 22 v.

SILVA, José Maria da Costa e. Ensaio biográfico-crítico sobre os melhores poetas portugueses. Lisboa: Imprensa Silviana, 1850-1855. $10 \mathrm{v}$. 